\title{
Case study of mind mapping as an educational tool for a pharmaceutical course on drug formulation design
}

\author{
Renata Miliani Martinez (iD), Felipe Rebello Lourenço ${ }^{(i)}$, André Rolim Baby \\ Department of Pharmacy, School of Pharmaceutical Sciences, University of São Paulo, São Paulo, Brazil
}

\author{
Keywords \\ Active-learning tools \\ Education \\ Mind mapping

\section{Correspondence} \\ Renata Miliani Martinez \\ 580 Prof. Lineu Prestes Avenue \\ Bl. 15 \\ 05508-900 \\ São Paulo \\ Brazil \\ remiliani03@gmail.com
}

\begin{abstract}
Objective: A method is presented for integrating the mind mapping methodology into Pharmacy course classes. An evaluation was made of the students' performance and their perception of achievement of significant learning.

Method: Weekly reviews and group assignments using mind maps were carried out on a Small-Scale Drug Formulation class concerning drug formulation design. The students' grades were compared with those for control groups and longitudinal Cohorts. A questionnaire was used to obtain the opinions of the students concerning the effectiveness of the methodology and their acceptance of it. $\quad$ Results: The students showed improved short-term performance and collective learning. Their feedback concerning the methodology was positive.

Conclusion: This strategy was shown to be a promising tool for engaging adult students in collaborative learning activities.
\end{abstract}

\section{Introduction}

Mind maps are graphical educational tools used to organise information into a network of ideas and their relationships. They take free forms, with lines connecting words, pictures, and/or diagrams around a central idea. The branches of a mind map are obtained by 'brainstorming' to create an association of topics. The technique is useful for understanding concepts, categorising them into specific domains, and determining the relationships among them, although it is often limited to improving memory and retaining knowledge (Davies, 2011). The information contained within passages of text can be hierarchically organised into mind maps, with previously acquired knowledge also being used to establish the connections. The cognitive process of structuring new information related to preceding concepts is called proactive facilitation. The main advantages of using this learning technique are the improved retention and recall of new information by proactive facilitation, especially when the original information is in written form (Farrand, Hussain, \& Hennessy, 2002). Mind maps can be considered as individualised and/or collaborative/ cooperative forms of organising knowledge.

Mind maps were first introduced by Buzan and Buzan, and have since been adapted for use in a variety of academic disciplines (1993). They are widely used in medical fields, due to the enormous amount of information that must be memorised. In previous studies concerning the short-term recall of information, the use of mind maps is controversial. Some studies showed no difference compared to learning techniques self-selected by 
undergraduate medical students (Shete, Garkal, \& Afroz, 2017; Wickramasinghe et al., 2012) while others showed improvement in the short-term retrieval of information (D'Antoni et al., 2010; Farrand et al., 2002). Long-term retention was observed after one week of assignments using this methodology, before adjusting the scores for baseline performance and motivation (Farrand et al., 2002; Kalyanasundaram et al., 2017). The definition of short- and long-term memory is controversial; however, the most accepted concept is that short-term memory has temporal decay and a limited chunk capacity (how many items short-term storage can hold) (Cowan, 2009). Mind maps can also be useful for teachers for preparing and reviewing lectures/course materials, since the information can be quickly written and reviewed, and can be easily updated (Edwards \& Cooper, 2010).

Although several public and private institutions are now using mind maps in their pedagogical practices, there are still few studies concerning the use of mind maps in Pharmacy courses at universities. Furthermore, most of the reported works have not used statistical approaches and/or English language, so they can be considered to be only of local interest (Czepula et al., 2018).

Pharmacy students are often overwhelmed by the amount of information they are required to correlate, memorise, and understand during their graduate courses. A good example is the Pharmaceutical Science discipline, taught to senior students, since its concepts require the integration of information from the areas of chemistry, biology, medicine, and pharmacology, among others. The students must be able to understand previous information, to assimilate the concepts needed for their professional practice. The design of drug formulations (tablets, capsules, creams, eye drops, ect.) is at the core of the Small-Scale Drug Formulation course and plays an important role in the training of pharmaceutical professionals. The present study investigates the effect of using mind maps on the performance of senior students of the Small-Scale Drug Formulation course, as well as their acceptance of this method as an educational tool. Mind mapping as a teaching methodology was primarily evaluated by the perceptions of the students regarding their achievement of significant learning, and secondarily by comparisons of mean scores with similar courses that did not utilise mind-mapping. Additionally, the authors sought to understand whether mind mapping had a longitudinal effect in subsequent coursework. The results of this study could be used to understand how the students interacted with the mind maps and to improve the learning methodology policies of the university.

\section{Methods}

This study was undertaken during the summer term of 2018. The Institutional Ethical Review Board approved this study. The 49 participants ( $12.0 \%$ male, mean age of 23 ) were senior students who attended the Small-Scale Drug Formulation course, focusing on a pharmaceutical science type of degree. Firstly, the basic structure of mind maps was explained to the students. A model of a mind map was used as an example (Chernyak, 2021). The students were encouraged to deliver clear and well-organised maps. They were required to work in self-selected groups of three to five individuals and to perform compulsory weekly assignments involving the creation of mind maps about the concepts presented in the classes.

The mapping activity was a part of the course and the grade associated with the submission and content assessment corresponded to $10.0 \%$ of the final course grade. The criteria for the scores was associated with a rubric (Swestyani et al., 2018). At the beginning of each weekly session, the lecturer also created a mind map to review the topics studied. The lecturer's map was presented after the student groups submitted their own. The lecturer's map was more superficial and cared for the connections between subjects (emulsions, tablets, suspensions, etc.) and the student's maps were more detailed in each subject. The mind maps could be produced by hand or by using software drawing tools (in the latter case, the name of the software should be referenced in the assignment). Students had freedom to choose their maps design approach to check their engagement with the assignment. The authors conducted two individual mandatory tests during the term (one every two months), corresponding to $90.0 \%$ of the final course grade $(45.0 \%$ per test). Tests involved eight open-ended items (short essays) focusing mainly on describing and explaining the principles and solving mathematical issues. The authors focused on the first three levels of the Bloom's Taxonomy (knowledge, comprehension and application)(Adams, 2015) to verify the association of ideas and memory retention skills addressed by mind mapping activities.

At the end of the term, the students were invited to answer a non-mandatory anonymous electronic questionnaire to evaluate the effect of the methodology in terms of their learning (four questions, shown in Figure 3). Questions 1 and 2 were used to evaluate students' perceptions of the effectiveness of mind mapping as a teaching tool. Questions 3 and 4 were intended to evaluate whether students would use the tool in other 


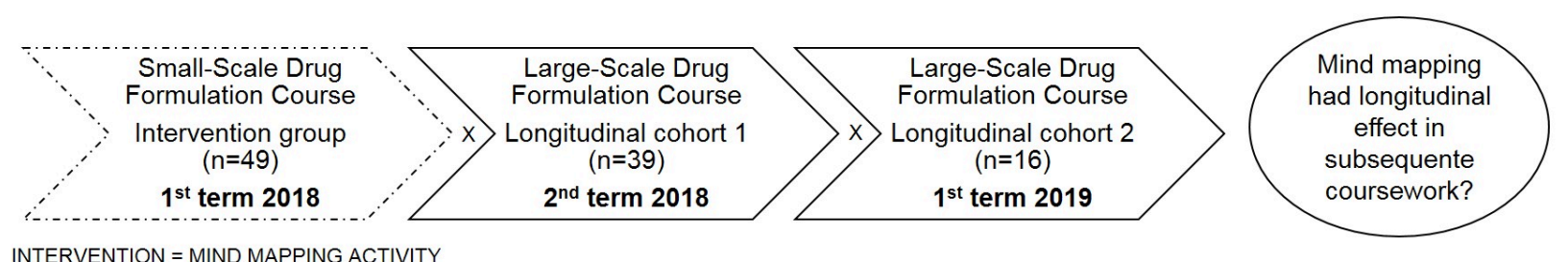

INTERVENTION = MIND MAPPING ACTIVITY

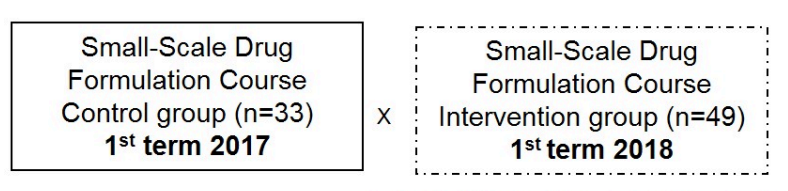

INTERVENTION = MIND MAPPING ACTIVITY

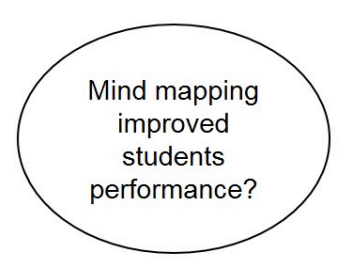

Figure 1: Flow chart and timeline for the consecutive cohorts, the control group, and the intervention group

courses. The completed questionnaires were analysed using the one-tailed Fisher exact test to evaluate the differences among the responses. The assumptions used for the null hypothesis were selected according to the institutional goals of achieving a) $85.0 \%$ student acceptance and participation in new learning methodologies, and b) at least $50.0 \%$ of students perceived that the tool had applicability for use in other courses. The relationships among the answers to the different questions were also analysed using correlation statistics. Other statistical analysis was conducted (chi squared tests and regression) however they were discharged for the lack of significance. The questionnaire survey received 45 responses, out of possible total of 49 , representing $92.0 \%$ participation.

The Small-Scale Drug Formulation course was a prerequisite for the Large-Scale Drug Formulation course, that covered almost the same concepts concerning drug formulation design, but without the mapping activity. The timetable was one term for small-scale processes (which were the objective of study in this work - intervention group (first term 2018)) followed by two terms for largescale processes (the first term with 39 students (longitudinal Cohort 1 (second term 2018)) and the second term with 16 students (longitudinal Cohort 2 (first term 2019))). Information about the students' overall course grades at the end of the term was compared between small- and large-scale courses, to understand whether the use of mind maps had longitudinal benefit in a similar subsequent course in which mind maps were not assigned. Students had two individual mandatory tests (one every two months, contributing to $50.0 \%$ grade for each test) using the same principles previous related for the small-scale course to achieve their final course grade.

Finally, information was also obtained for another group of students who had attended the Small-Scale Drug Formulation course one year before this work, employed as the control group (33 students who had not received any mind map assignments - control group (first term 2017)). Students' final course grades at the end of the term were compared between the intervention and control groups to verify if mind mapping activities were beneficial to improving student's performance during the small-scale course. A flow chart describing each group and the design of data evaluation is available in Figure 1. Students selected their own groups within classes to deliver the assignments, to avoid any unintentional increase in stress due to working with people they were unfamiliar with. In the institution, students can choose their own courses in each term, hence it was not possible to maintain the same group across longitudinal cohorts.

The final course grades, the mean test grades and the mean mind map assignments grades (ranging from 0.00 to 10.0) were used to compare the students' performance. The institutional policy requires a final course grade equal or higher than 6.00 to pass. The percentage of approval (rate of students that passed the course) is also an interesting indicator of student's performance and used in this work. No active learning methodology was employed with the other groups used for comparison (longitudinal Cohort 1 and 2 and control group). Histograms were constructed to show the final course grade distributions and ANOVA was applied to identify significant differences between the mean of final course grades. $A$ value of $\alpha=$ 
0.05 was adopted for statistical significance. All the statistical analyses were performed using Minitab version 18 (Minitab Inc., Pennsylvania, USA).

\section{Results}

The student's mind maps were organised, clear, and easy to understand. Figure 2 shows an example of a mind map concerning suspensions, designed by one of the student groups using CmapTools software.

Most of the students chose to categorise the subjects according to a two-layer 'tree' diagram, using bullet points to divide the secondary (explanatory) information. Very few groups used colours to design their maps, however those groups were the ones that showed higher engagement and achieved higher grades. The mapping activity was delivered on time by all the groups. The mean score for the mind map assignments was 8.85 , while the mean score in the tests was 7.75. The mean final course grade was 7.82 and $100 \%$ of students passed the SmallScale Drug Formulation course (all students in the intervention group passed the course). The control group had a mean final course grade of 7.79 with $100 \%$ of approval (all students in the control group passed the course). However, the students who attended the LargeScale Drug Formulation course (one year after the intervention) showed a mean score of 7.79 with $97.0 \%$ of approval $(97.0 \%$ of students in the longitudinal Cohort 1 passed the course) in the first term and a mean score of 6.65 with $81.0 \%$ of approval $(81.0 \%$ of students in the longitudinal Cohort 2 passed the course) in the second term. After testing for normality, application of ANOVA showed that all the mean grades were statistically equal, except for the scores for the second term of the LargeScale Drug Formulation course. The grade histograms (Figure 3) showed normal distributions for all the groups, with narrower peak profiles for the cases where mind maps were used as an intervention.

Most of the students believed that the mind mapping methodology was effective for retaining the concepts and had no difficulties in understanding how it worked. They would consider using mind maps in the study of other disciplines and would like more disciplines to use this methodology (Table I). The one-sample proportion test was used to evaluate the statistical significance of the data (Table I).

At a $95 \%$ confidence interval, it was found that:

- at least $85 \%$ of the students believed that the mind map methodology was effective for retaining the concepts taught throughout the discipline;
Table I: Summary of the survey questions, the responses, and the one-sample proportion test, considering the null hypothesis $(p)$ and the $p$-value.

\begin{tabular}{|c|c|c|c|c|}
\hline Question & $\begin{array}{l}\text { Yes } \\
\text { responses }\end{array}$ & $\begin{array}{l}\text { No } \\
\text { responses }\end{array}$ & $p$ & $p$-value \\
\hline $\begin{array}{l}\text { Do you believe that the } \\
\mathrm{m} \text { in d m a p p ing } \\
\text { methodology was } \\
\text { effective for retaining } \\
\text { the concepts throughout } \\
\text { the discipline? }\end{array}$ & $43(96.0 \%)$ & 2 (4.0\%) & 0.85 & 0.027 \\
\hline $\begin{array}{l}\text { Did you have any } \\
\text { difficulties in unders- } \\
\text { tanding how the mind } \\
\text { mapping methodology } \\
\text { worked? }\end{array}$ & $2(4.0 \%)$ & 43 (96.0\%) & 0.15 & 0.027 \\
\hline $\begin{array}{l}\text { Would you consider } \\
\text { using the mind mapping } \\
\text { methodology to study } \\
\text { another discipline? }\end{array}$ & $31(69.0 \%)$ & 14 (31.0\%) & 0.50 & 0.008 \\
\hline $\begin{array}{l}\text { Would you like other } \\
\text { disciplines in your phar- } \\
\text { macy curriculum to also } \\
\text { use the mind mapping } \\
\text { methodology? }\end{array}$ & $30(67.0 \%)$ & 15 (33.0\%) & 0.50 & 0.018 \\
\hline
\end{tabular}

-fewer than $15 \%$ of the students had difficulties in understanding how the mind map methodology worked; -more than $50 \%$ of the students considered using the mind map methodology in the study of other disciplines;

-over $50 \%$ of the students would like more disciplines of the Pharmacy course to use the mind map methodology.

The groups of answers were analysed in pairs. The analysis showed no evidence of correlation between the question pairs $1: 2$ and $2: 3$, since the $p$-values were $>0.05$. The Pearson correlation coefficients showed a negative correlation for the question pair 2:4 and positive correlations for the question pairs 1:3, 1:4, and 3:4, although the correlations were weak $(<0.5)$ in all cases. These correlation analyses provided internal validation of the approach adopted.

\section{Discussion}

The students produced good quality mind maps that were concise, objective, clear, and organised according to the rubric designed by Swestyani and colleagues (2018). Most of the students preferred to design the maps using software tools such as the IHMC CmapTools package (http://cmap.ihmc.us)(Cañas Alberto J, Novak Joseph D, 2004). The use of software tools enables students to cooperate in groups, as a useful way to share their 


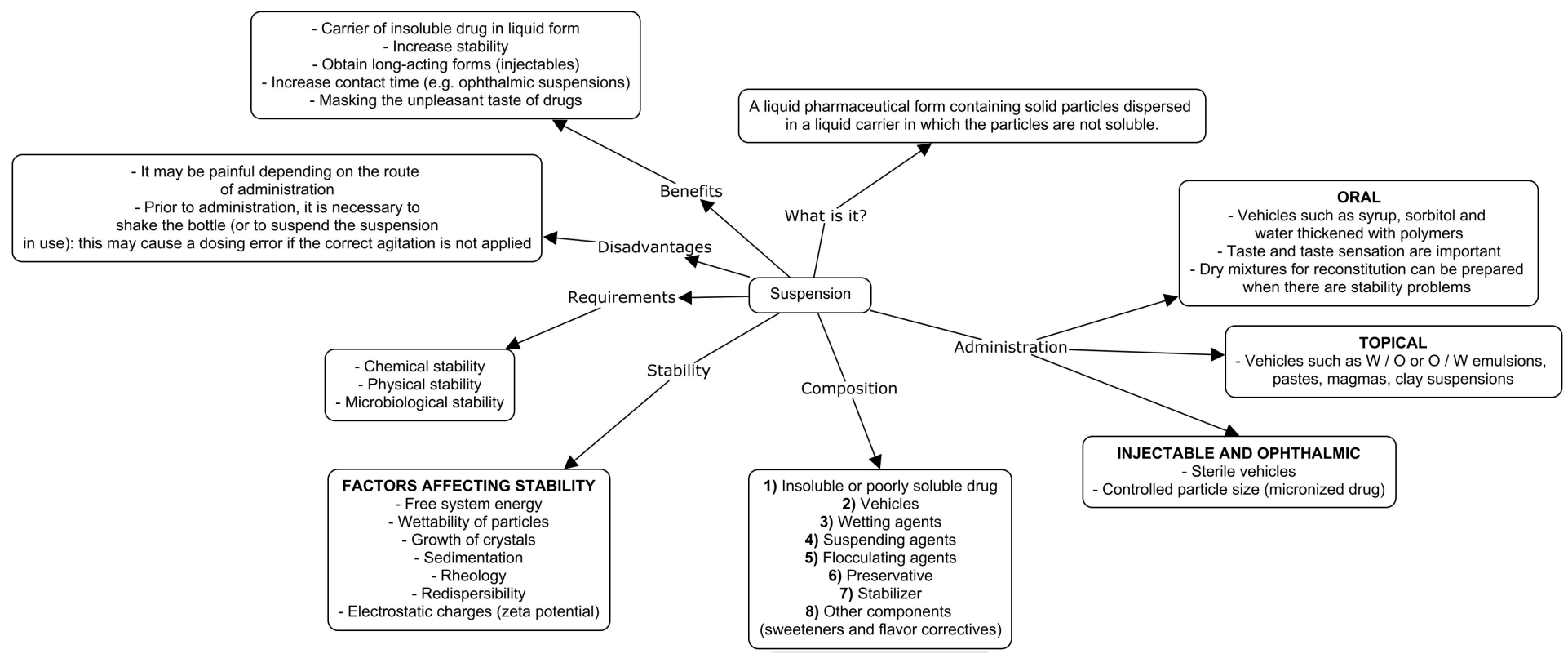

Figure 2: Mind map about suspensions (adapted from Portuguese)

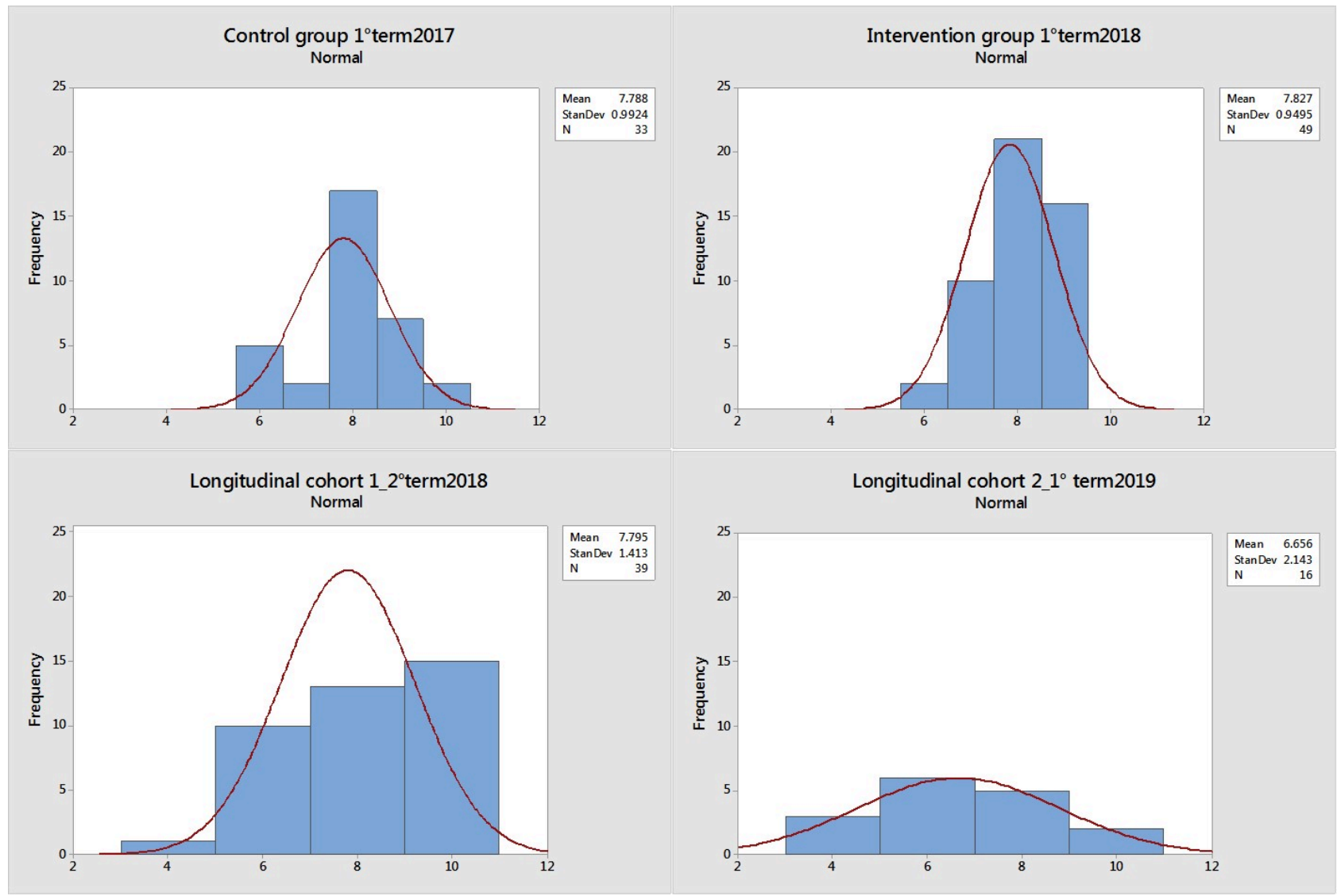

Figure 3: Grade distribution histograms for the Small- (intervention and control groups) and Large-Scale Drug Formulation (longitudinal Cohorts 1 and 2) courses 
knowledge and learn from the inputs of colleagues (Vink et al., 2015). There is also an interesting psychological perception that mind mapping is not 'busywork' when the maps are created in a cooperative way (Hill, 2004). However, since the contents of Pharmaceutical Science disciplines (Small- and Large-Scale Drug Formulation course) are extensive, students could feel overloaded by cognitive inputs when combining their maps for the entire term. For this reason, studies have shown that integration between mind maps and other tools, especially those that are web-based, can be a promising strategy for enhancing learning performance when using these maps (Chiou, Tien, \& Lee, 2015; Hwang et al., 2014). Since the background of the students is an important factor influencing the quality of mind maps (Svanström et al., 2018), the methodology proposed in this study may be a valuable tool in the development of adult learning strategies. Suggestions provided to the students, such as the presentation of several linking words, could assist them in designing mind maps that then evolve into conceptual maps (Nonose et al., 2016).

Although critical thinking skills are required in the subsequent professional activities of pharmaceutical students, many courses still use assignments and tests that emphasise memorisation. Mind maps can be successfully used in medical training to improve both critical thinking and memorisation (D'Antoni et al., 2010). The present findings revealed no significant difference between the mean scores of the control group and the intervention group. The histogram showed a shift of the peak to higher scores, however, indicating that the mind maps affected the students, as a group, in a way that reflected a more homogeneous and harmonised form of learning. The authors believe that in the short term, students could benefit from the use of mind maps as a memorisation tool to improve understanding, as well as to regulate the depth of concepts. The use of mind maps to improve the shortterm retrieval of information has previously shown good results when compared to 'standard-note taking' or other 'self-selected study' techniques (D'Antoni et al., 2010; Farrand et al., 2002).

Considering the students' performance after one year of the intervention, the histograms showed broader peaks and the mean scores were lower. For the classes concerning large-scale processes, the heterogeneity of the data highlighted the individual contribution of each student to the mean score, in contrast to the mind map methodology, where there was collective learning using shared maps (Stokhof et al., 2018). Besides, there was no significant evidence that the intervention influenced the long-term learning of the students after one year, in agreement with the one-week findings of Farrand and colleagues, after adjusting the scores for baseline performance and motivation (Farrand et al., 2002). Since the material used during the large-scale course was different from the small-scale (though related), and the overall course grade is not the best form of assessment (Schinske, \& Tanner, 2014), the percentage of approval (rate of students that passed) may be used to speculate on the role of mind mapping in the learning process. Mind mapping activities were perhaps able to elucidate the understanding and links between the content and, for that reason, $100 \%$ of students were able to pass the course.

Methodologies, such as mind maps, that can integrate concepts, reveal their relationships, and assist in information recall can be highly useful during the learning process. In Brazil the Ministry of Education (MEC) is the government regulatory agency responsible for the pedagogical policies and practices used in basic, intermediate, higher, and postgraduate education at public and private institutions. The MEC has developed strategies and standard examinations for evaluation of all educational levels throughout the country. Such evaluation is focused on achieving integration and systematisation of the various areas of knowledge. Higher education is specifically evaluated by the National Examination of Student Performance (ENADE). This examination is intended to encompass several dimensions and to cover learning during the entire course (rather than just checking the performance of the students at the end of the course), giving greater weight to general professional skills, with emphasis on cross-cutting and multidisciplinary themes (Verhine, Dantas, \& Soares, 2006). This evaluation occurs every three years and covers all the content of graduate courses. The ENADE also provides an indirect way of evaluating both the course and the educational institution. Consequently, the performance of the students can drive internal policies and changes in curricula.

Although the efforts of teachers/professors to improve their pedagogical practices, as a strategy to improve ENADE scores, significant learning involves a combination of several variables and is a highly individual process. The use of mean scores is probably not representative of this complex process, although the mean score is an objective variable that can be easily measured and used for the comparison of groups. Therefore, the questionnaire survey was also used to evaluate the acceptance of the technique by the students and to analyse their subjective opinions. The high percentage of students (96.0\%) who had a good perception of the retention of concepts, achieved using mind maps, indicated that this learning 
methodology could potentially be introduced in other classes. Although this was not the first time that the students had been presented with the mind map methodology, they were still not fully comfortable in using it. Active learning is a gradual process and a single semester is not enough time to allow the development of a high level of mapping skills or to fully understand the benefits of the method. This could also provide an explanation for the lack of significant long-term retention.

For the Brazilian university students, balancing the study time and the depth of content to be covered is probably the greatest challenge in the classes. Most of the students spend substantial periods of their time working to be able to pay the faculty fees. Students with this profile tend to show low time commitments for the preparation of active learning materials (Noble et al., 2011). For this reason, the authors believe that the weekly awarding of grades encouraged the students to deliver their assignments on time. Another benefit of mind maps for adult learners is that the hierarchical structures of the maps may be very helpful for assisting busy college students in understanding the big picture, enabling them to decide how deeply they are willing to study for each component.

Despite the weak correlations between the questions, the students' evaluations showed coherence. Those who had difficulty in understanding how mind mapping worked were not willing to use this type of methodology again during their courses. In contrast, those who believed that the learning methodology was effective were willing to use it again. This information is important to the instructor, since the incorporation of mind maps, as assignments, requires in-depth planning and understanding of the learning objectives (Hill, 2004). It also plays an important role in the policies of the educational institution regarding teaching-learning methodologies. Teachers personally motivated to use active learning tools (those who aspired to new challenges and knowledge) were shown to dedicate additional class time to such methodologies and to encourage the institution to use various new strategies in the classroom (Rockich-Winston et al., 2018). In this way, when a greater number of instructors and lecturers use the same methodology, both the institution and the students can benefit from cooperative working, greater motivation, and improved integration. However, teachers who are willing to use active learning methodologies may require more time for planning and structuring different ways to evaluate the efficacy of their approaches, in addition to the assignment of grades.

Finally, the subjective opinions of the students were important for understanding the motivational role of mind maps in their learning processes. Students typically give positive feedback about active learning tools, especially when they work in groups (Gavaza, Campbell, \& Mullins, 2012; Tatachar et al., 2016). In the present study, most of the students provided positive feedback about the use of mind maps. It is important to clarify that the survey was performed after the assignments, after the test results had been graded, so that the students would not feel that they were under any social pressure to positively evaluate the methodology. We considered this intervention group as a pilot trial to evaluate the formal use of mind maps in the Pharmacy course at University of Sorocaba, São Paulo, Brazil. The results showed that the use of mind maps still needed to be adapted to enable them to be appropriately incorporated in the schedules of the students and lecturers. Further research should be conducted to explore the effects on the mind map method of other variables such as demographic factors, intervention frequency, and the influence of previous methodologies

\section{Acknowledgments}

The authors would like to thank the Pharmacy course at University of Sorocaba for allowing the development of this research.

\section{References}

Adams, N.E. (2015). Bloom's taxonomy of cognitive learning objectives, Journal of the Medical Library Association, 103(3), 152-153. https://doi.org/10.3163/1536-5050.103.3.010

Buzan, T., \& Buzan, B. (1993). The Mind Map Book How to use radiant thinking to maximize your brain. BBC Books, Ed., London

Cañas Alberto J., \& Novak Joseph D.G.F. (2004). Concept Maps: Theory, Methodology, Technology. In G. F. Cañas Alberto J, Novak Joseph D (Ed.), Proceedings of the first international conference on concept mapping (125-133). Pamplona, Spain.

Chernyak, P. (2021) How to Make a Mind Map (online). Available from: https://www.wikihow.com/Make-a-Mind-Map

Chiou, C.-C., Tien, L.-C., \& Lee, L.-T. (2015). Effects on learning of multimedia animation combined with multidimensional concept maps. Computers \& Education, 80, 211-223. Pergamon. https:// doi.org/10.1016/j.compedu.2014.09.002

Cowan N. (2008). What are the differences between long-term, short-term, and working memory?. Progress in brain research, 169, 323-338. https://doi.org/10.1016/ S0079-6123(07)00020-9 
Czepula, A.I. dos S., Bottacin, W.E., Júnior, E.H., Pontarolo, R., \& Correr, C.J. (2018). Active methodology and blended learning: An experience in pharmaceutical care. Currents in Pharmacy Teaching and Learning, 10(1), 106-111. https://doi.org/ 10.1016/j.cptl.2017.09.013

D’Antoni, A.V., Zipp, G.P., Olson, V.G., \& Cahill, T.F. (2010). Does the mind map learning strategy facilitate information retrieval and critical thinking in medical students? BMC Medical Education, 10(1), 61. https://doi.org/ 10.1186/1472-6920-10-61

Davies, M. (2011). Concept mapping, mind mapping and argument mapping: what are the differences and do they matter? Higher Education, 62(3), 279-301. Springer Netherlands. https://doi.org/10.1007/s10734-010-9387-6

Edwards, S., \& Cooper, N. (2010). Mind mapping as a teaching resource. Clinical Teacher, 7(4), 236-239. https://doi.org/ 10.1111/j.1743-498X.2010.00395.x

Farrand, P., Hussain, F., \& Hennessy, E. (2002). The efficacy of the 'mind map' study technique. Medical Education, 36(5), 426-431.

Gavaza, P., Campbell, J., \& Mullins, R. (2012). Pharmacy students' opinions toward active learning in the didactic curriculum. Currents in Pharmacy Teaching and Learning, 4(4), 273-277. http://dx.doi.org/10.1016/j.cptl.2012.06.002

Hill, L.H. (2004). Concept Mapping in a Pharmacy Communications Course to Encourage Meaningful Student Learning. American Journal of Pharmaceutical Education, 68(5), 109. American Association of Colleges of Pharmacy. http://www.ajpe.org/doi/abs/10.5688/aj6805109

Hwang, G.-J., Kuo, F.-R., Chen, N.-S., \& Ho, H.-J. (2014). Effects of an integrated concept mapping and web-based problemsolving approach on students' learning achievements, perceptions and cognitive loads. Computers \& Education, 71, 77-86. Pergamon. Available from: https:// www.sciencedirect.com/science/article/pii/ S0360131513002686

Kalyanasundaram, M., Abraham, S., Ramachandran, D., Jayaseelan, V., Bazroy, J., Singh, Z., \& Purty, A. (2017). Effectiveness of mind mapping technique in information retrieval among medical college students in Puducherry-A pilot study. Indian Journal of Community Medicine.

Noble, C., O'Brien, M., Coombes, I., Shaw, P.N., \& Nissen, L. (2011). Concept mapping to evaluate an undergraduate pharmacy curriculum. American journal of pharmaceutical education, 75(3), 55. American Association of Colleges of Pharmacy. Available from: http://www.ncbi.nlm.nih.gov/ pubmed/21655409

Nonose, K., Okukubo, A., Yoda, Y., Kanno, T., \& Furuta, K. (2016). Support for creating introspective reports detailing cooperative behaviors with concept maps. Cognition, Technology \& Work, 18(1), 71-88. Springer London. Available from: http:// link.springer.com/10.1007/s10111-015-0347-x

Rockich-Winston, N., Train, B. C., Rudolph, M. J., \& Gillette, C. (2018). Faculty motivations to use active learning among pharmacy educators. Currents in Pharmacy Teaching and Learning, 10(3), 277284. https://doi.org/10.1016/j.cptl.2017.11.015

Schinske, J., \& Tanner, K. (2014). Feature Approaches to Biology Teaching and Learning Teaching More by Grading Less ( or Differently ). CBE-Life Sciences Education, 13, 1-8.

Shete, A., Garkal, K., \& Afroz, S. (2017). Effectiveness of mind maps as a self-learning tool in 1st year MBBS students of an Indian medical college. National Journal of Physiology, Pharmacy and Pharmacology, 1.

Stokhof, H., de Vries, B., Bastiaens, T., \& Martens, R. (2018). Using Mind Maps to Make Student Questioning Effective: Learning Outcomes of a Principle-Based Scenario for Teacher Guidance. Research in Science Education, 1-23. Research in Science Education.

Svanström, M., Sjöblom, J., Segalàs, J., \& Fröling, M. (2018). Improving engineering education for sustainable development using concept maps and multivariate data analysis. Journal of Cleaner Production, 198, 530-540. Elsevier. Available from: https:// www.sciencedirect.com/science/article/pii/S0959652618320377

Swestyani, S., Masykuri, M., Prayitno, B.A., Rinanto, Y., \& Widoretno, S. (2018). An analysis of logical thinking using mind mapping. Journal of Physics: Conference Series, 1022(1).

Tatachar, A., Li, F., Gibson, C.M., \& Kominski, C. (2016). Pharmacy students' perception of learning and satisfaction with various active learning exercises. Currents in Pharmacy Teaching and Learning, 8(4), 577-583. http://dx.doi.org/10.1016/j.cptl.2016.03.019

Verhine, R.E., Dantas, L.M.V., \& Soares, J.F. (2006). Do Provão ao ENADE: uma análise comparativa dos exames nacionais utilizados no Ensino Superior Brasileiro. Ensaio: Avaliação $e$ Políticas Públicas em Educação, 14(52), 291-310. Available from: http://www.scielo.br/scielo.php? script=sci_arttext\&pid=S0104-40362006000300002\&lng=pt\&tlng=pt

Vink, S.C., Tartwijk, J. Van, Bolk, J., \& Verloop, N. (2015). Integration of clinical and basic sciences in concept maps: a mixed-method study on teacher learning. BMC Medical Education, 15, 20. BioMed Central. Available from: http://www.ncbi.nlm.nih.gov/pubmed/25884319

Wickramasinghe, A., Widanapathirana, N., Kuruppu, O., Liyanage, I., \& Karunathilake, I. (2012). Effectiveness of mind maps as a learning tool for medical students. South East Asian Journal of Medical Education, 1(1), 30-32. Available from: http://archive.cmb.ac.lk/ research/bitstream/70130/148/1/9.pdf 